\title{
Culture and Stock Market Impact From Bad News Announcements
}

\author{
Jiangxia Liu \\ Valparaiso University
}

Bad news causes a decline in the stockholder's wealth. However, the magnitude of the impact varies between studies. Intending to explain the different impacts observed, we explore the factors affecting the extent of stock impact from bad news announcement. Event Study Methodology is used to analyze data from the US, India, and Japan. The rich multinational data allows the comparison of stock impact between countries. We find that disruptions cause stock decline; however, the magnitude of reduction varies between countries. We argue that national culture plays a vital role in planning and management strategies, affecting mitigation and continuity strategies.

Modern companies are multinational and operate in multiple countries. Despite this, national culture is ingrained in their management styles. To explore this, we also study companies traded on stock markets outside their domicile country. We find that national culture has a strong influence on planning and preparedness. Cultural orientation impacts resiliency. We argue that investors realize the importance of culture as company domicile affects the stock impact from bad news.

Keywords: bad news, event studies, stock market impact

\section{INTRODUCTION}

Financial markets are considered efficient in incorporating the performance of a company or the economy in general. The announcement of good or bad news has implications for the return on investment from companies. In publicly traded companies, such information results in a change in the stock returns for the investors. The extent of the change depends on the nature of the news. Research streams in finance, accounting, and operations management have used the stock returns to assess the impact of information emanating from public news releases.

Research has used a variety of bad news events to assess their impact on stock returns. One such class of news events is disruptive events that hamper a company's ability to perform its day-to-day operations, potentially impacting financial performance. Such events are often referred to as supply chain disruptions or glitches. This article focuses on bad news originating from such announcements. As expected, these events hurt the stock market. However, the magnitude of stock decline varies between studies. In this study, we explore various factors that may help understand the reasons behind the variability in the stock decline. More specifically, we explore the cultural aspects that affect a company's operations as a source of variation. Both national and company culture are explored and investigated to reveal their impact on the impact of disruptions on financial performance measured through the stock market impact. 
According to Mello and Stank (2005), culture consists of a shared understanding of organizational issues, objectives, and practices. National culture is the collective mental programming of a country's people (Hofstede et al., 2010). Research related to cross-national research focuses on shared cultural values as a primary course of differentiating between nations (Tsui et al., 2007). Pagell et al. (2005) state, "national culture is an equally relevant lens" to view and understand the country-specific "systematic differences...to advance the field of operations management." Past research has shown that national culture affects planning and operational decision-making in organizations.

Both national and organizational culture factors play an important role in decision-making and influence the disruption planning, response, and recovery. For example, many factors related to Japanese culture are attributed to superior management abilities in companies with Japanese culture. These factors include collaborative spirit, trust, capability sharing (Sheffi, 2007), supplier association, and Keiretsu, all of which foster confidence-building and capability sharing among firms (Whitney et al., 2012).

This research builds on Hendricks and Singhal (2003), Kumar, Liu, and Scutella (2015), and Kumar, Liu, and Demirag (2015) and other work on understanding the impact of operational disruptions or glitches on stock market performance. The above papers underline the importance of effective supply chain management by revealing the financial impact of a 'glitch' in operations. Their analysis is entirely based on supply chain disruptions in companies traded in the U.S. stock markets. We, however, focus on companies in three countries. The underpinning of our work is that learning and theories applicable to supply chains in the U.S. may not be directly applicable to supply chains in other parts of the world (Zhao et al., 2006). Also, considering countries from different parts of the world could help understand cultural differences in stock consequences from supply chain disruptions.

Besides studying operational disruptions in three countries, we also explore the reasons for the difference in the stock impact from the public announcement of such events. We especially invoke the research on the effects of culture on disruptions planning and mitigation to explain the differences in stock impact from disruptions observed in the countries of Japan, India, and the U.S. Furthermore, to elaborate on the effect on company culture on disruptions management as we study the stock returns from Japanese automakers that are traded in the stock market in the U.S.

Figure 1 outlines the conceptual model. The model is based on literature that indicates that companies in different countries have a varying degree of disruptions planning and mitigation abilities. Moreover, Hofstede's national culture dimensions argue that countries are different. We specifically use Hofstede's dimensions of Uncertainty Avoidance and Long-term orientation. Countries with high values of these dimensions are expected to plan and prepare for low probability disruptive events, which in turn could help limit the impact of disruptions. Investors take note of the national and company culture and punish wellprepared companies lesser in the event of a disruption, primarily because they may perceive these companies to be well prepared and recover faster from disruptions.

This research aims to answer the following questions: 1) How do stock consequences from disruptions vary between countries? 2) Could national culture help explain the difference in stock impact from the public announcement of disruptions? 3) Does company culture (often based on the country of domicile) help answer the differences in stock impact? Our study is of interest to investors and operations managers as it could help understand the factors affecting the impact of disruptions on the stock market. Part of this paper is motivated by the following studies Kumar, Liu, and Scutella (2015), Filbeck, Kumar, Liu, and Zhao (2015), and Filbeck, Kumar, Zhao (2014). Other results are new for literature.

Our analysis indicates that supply chain disruptions cause a stock decline in all three countries considered. However, the magnitude of decline varies. Markets in Japan and India show a significant decline as early as 3 to 6 days before the disruption announcement day. The U.S. markets did not register a decline until the announcement date. Maturity of the stock market, development status of a country, and financial trading legislation could help explain the differences in the level of stock decline and the time of decline. National and company culture could also partially help explain the difference in stock impact.

The rest of the paper is organized as follows. Section 2 presents relevant literature. Section 3 discusses the event study methodology and other theoretical underpinnings of this study. Section 4 reports the findings. Finally, Section 5 concludes the paper. 


\section{FIGURE 1 \\ CONCEPTUAL RESEARCH MODEL}

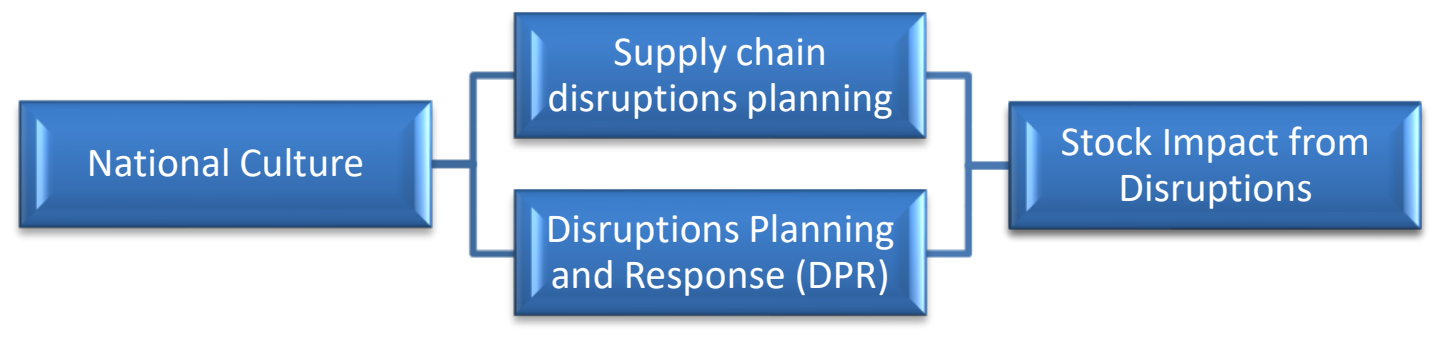

\section{LITERATURE REVIEW}

The literature relevant to this paper falls into the domain of stock market impact from disruptions, organizational culture, and national culture. Accordingly, we present literature from these three streams.

There is a rich stream of literature dealing with the management of operational disruptions and glitches. Studies have focused on planning, preventing, and mitigating disruptions. The literature covers multiple academic research areas. Ellis, Shockley, and Henry (2011) and Craighead, Blackhurst, Rungtusanatham, and Handfield (2007) provide comprehensive literature reviews. Our research is in the domain of estimating the value of effective supply chain management by observing the financial consequences when supply chains experience disruptions. Within this domain, we focus on exploring country differences, national culture, and organizational culture.

Quantitative indicators to assess the effectiveness of management and operations strategies are challenging to develop. Therefore, research uses conceptual framework and case studies to provide anecdotal evidence to report the efficacy and applicability of strategy. Another method is to establish a correlation between the effectiveness of operational decisions and shareholder value (Mentzer, 2001; Chopra \& Meindl, 2012). Some research has shown that supply chain management could lead to enhanced shareholder wealth. Another stream, more relevant to this research, has taken a different approach to assessing the financial benefits of effective management. Research in this domain studies the stock impact of bad news. A portion of our research falls in this category. The central assumption is that the level of stock price decline should reflect the severity of the bad news in realizing the company's short- and longterm profitability. In a seminal paper, Hendricks and Singhal (2003) applied these ideas to show that glitches in organizations lead to a stock price decline. They demonstrate a statistically significant decrease in shareholder value after the announcement of glitches. Factors such as firm size, growth prospect, and industry category were shown to impact the stock decline. Hendricks and Singhal (2005a and 2005b) extended the results to include the impact on the stock price for two years, one-year pre- and post-glitches period. The equity risk was higher by $13.5 \%$ in the year following the disruption for the disrupted companies.

Filbeck, Kumar, Liu, and Zhao (2015) explore the impact of the market cycle and company domicile on stock performance, while Filbeck, Kumar, and Zhao (2014) explore contagion across competitors in the event of a disruption. Competitors are found to experience adverse stock reactions indicating that negative stock consequences of disruptions are not limited to the companies affected and cause losses for competitors. Kumar, Liu, and Scutella (2015) extend the results to the Indian stock market.

Economic and cultural factors affect the applicability and effectiveness of management practices. Policies deemed effective in one country may not be suitable for other countries. Research has focused on this aspect as Zhao et al. $(2006,2007)$ called for investigation directed especially in developing countries. They use China as an example and cite economic, governmental, and cultural differences as motivations for research specifically focused on China. They also outline the differences in the supply chain in China and that in western countries. 
Similarly, Sahay and Mohan (2003) and Sahay et al. (2006) outline supply chain characteristics in India. Jayaram and Avittathur (2012) outline the challenges that western companies may face in operating under supply chain structures prevalent in India. They also motivate the need for research specifically focused on these countries.

Our research has some support from accounting and finance literature. Literature in these areas has extensively documented the effect of various events on the company as well as competitor stock performance. Some of these events include new major orders (Galy \& Germain, 2007), significant dividend announcements (Laux, Starks, \& Yoon, 1998), bankruptcy announcements (Helwege \& Zhang, 2013), litigation (Hadlock \& Sonti, 2012), acquisitions (Stillman, 1983), leveraged buyouts (Chevalier, 1995), new product introductions (Chen et al., 2002), stock repurchases (Hertzel, 1991), and international cross-listings (Melvin \& Valero-Tonone, 2003).

Research in international management is rich in identifying the correlation between national culture and business practices. Many of these studies use the quantitative measures of national culture developed by Hofstede. The dimensions developed by Hofstede (2013) are derived using factor analysis of large-scale data from 72 countries. The five dimensions thus developed measure the similarities and differences between national cultures. Subsequent research has reaffirmed the validity of these measures (Merritt, 2000). Other measures of national culture were developed by the GLOBE project (Javidan and House, 2001), Trompenaars and Hampden-Turner (1998), and Schwartz (1994). However, despite limitations, Hofstede's measures are widely accepted to be valid for business applications (Magnusson et al., 2008). See Wiengarten et al. (2011) for a description of other measures and the applicability of Hofstede's measures.

Studies have shown that national culture impacts business decisions. For example, decisions in Western companies are sometimes focused on short-term returns, while in many Asian companies, decisions are motivated by long-term effects. Other significant differences include short-term employment and individual responsibility and decision-making in American companies. Many Asian companies have lifetime employment, consensual decision-making, and collective responsibility (de Koster and Shinohara, 2006). Literature on national culture demonstrates the difference between countries and offers explanations to account for the difference in business strategies, such as international expansion, the low cost versus differentiation, compensation schemes, and choice of financial structure (Pagell et al., 2005). Dunning and Pearce (1982) and Porter (1990) argue that the home country of the company and the physical location of facilities and personnel affect business decisions. To understand the business impact of national culture, Katz et al. (1999) and Nakata and Sivakumar (1996) call for studying the association of national culture and operational decisions in operations management.

Roh et al. (2008) attribute cultural orientations for the difference in productivity gap between American and Japanese companies. Studying manufacturing data from six countries, Naor et al. (2008) conclude that the organizational culture could explain differences in manufacturing performance across countries. Wiengarten et al. (2011) study the moderating influence of Hofstede's national cultural dimensions on investment in manufacturing facilities and quality practices. They found that Individualism moderates both facilities and quality investment, while Masculinity and Uncertainty Avoidance moderate only the quality practices. McGinnis and Spillan (2012) attribute culture to the differences in logistics strategies between the U.S. and Guatemala. Other research has shown the association between national culture and total quality management (Katz et al. 1998), innovation (Panida et al., 2011), supplier selection (Carter et al., 2010), product characteristics (Desislava, 2010), and product development (Nakata and Sivakumar, 1996). Kaasa and Vadi (2010) conclude that innovativeness is higher in companies located in countries with high Power Distance, Uncertainty Avoidance, Collectivism, and low Masculinity.

Cultural orientation is particularly important when making supply chain disruptions decisions (Dowty and Wallace, 2010). They use cultural biases to characterize interactions among organizations during humanitarian supply chain disasters. The four cultural biases identified by Dowty and Wallace (2010) are hierarchic, individualist, fatalist, and egalitarian. Management effectiveness and interactions between companies are found to be influenced by these cultural biases. Jia and Rutherford (2010) address supply chain relational risk associated with cultural differences between companies from China and the West. They suggest that companies must adapt according to local culture to be successful. 


\section{DATA AND METHODOLOGY}

\section{Data}

The US, India, and Japan are open market and democratic countries and allow press and media freedom. Therefore, we expect the media outlets to report on important events, including company-related news of public interest. Our disruptions data is derived from Dow Jones News Service (U.S.), Wall Street Journal (U.S.), The Economic Times (India), The Japan Times (Japan), and Nikkei (Japan).

To compile disruptions data, full-text articles were searched in all the relevant new release sources for ten years, from January 1, 2003 to December 31, 2012. The keywords searched included terms that would imply various categories of bad news for the company. Some of the terms include breakdown, issues, delays, shortfall, poor planning, inaccuracies, worker strike, accidents, data breaches, fire, earthquake, and ethical complaints. The keywords were selected to cover bad news related to operations and planning in a company. Whole texts were read to ensure that the news release is regarding a bad news event.

Our initial data included many disruption points. In compiling the final data, we dropped companies that are not publicly traded. We also removed the disruption data if the company did not have stock information surrounding the date of disruption. The resulting data is 313 (the U.S.), 301 (India), and 216 (Japan). Stock market data is obtained for respective countries through Yahoo finance and the CRSP database.

For measuring the cultural aspects, we use widely accepted measures of national culture developed by Hofstede (1980), which were then restudied over time (Hofstede, 2013). The measures provide a quantitative scheme to measure national culture. Specifically, culture is measured in five dimensions: power distance, Uncertainty Avoidance, Individualism, Masculinity, and Long-term Orientation. Hofstede (2013) and Pagell et al. (2005) describe these dimensions. These five dimensions have been successfully used to explain cross-country differences in many fields, including organization behavior, information technology, human resources, marketing, and management. Example applications of Hofstede dimensions could be found in Desislava (2010) and Rujirawanich et al. (2011). Following Kumar, Liu, and Demirag (2015), we think about the dimensions of Uncertainty Avoidance and Long-term Orientation in understanding the stock impact from bad news. Table 1 reports the three dimensions for India, Japan, and the U.S.

TABLE 1 HOFSTEDE INDICES

\begin{tabular}{lccc}
\hline \hline & India & Japan & U.S. \\
\hline Uncertainty Avoidance & 40 & 92 & 46 \\
Long-term Orientation & 51 & 88 & 26 \\
\hline
\end{tabular}

(Obtained from https://www.hofstede-insights.com)

Uncertainty Avoidance reflects the extent to which people and, as a consequence, companies feel uncomfortable with uncertainty and ambiguity. In countries with high Uncertainty Avoidance, individuals, organizations, and societies plan for and tend to avoid uncertainty. Some of these differences occur across countries in the form of different laws, rules, regulations, and the use of technology (Pagell et al., 2005). According to Hofstede (2013), "Countries exhibiting strong Uncertainty Avoidance Index maintain rigid codes of belief and behavior and are intolerant of unorthodox behavior and ideas. Weak Uncertainty Avoidance Index societies maintain a more relaxed attitude in which practice counts more than principles." High Uncertainty Avoidance implies low tolerance to ambiguity. Therefore, we expect companies in countries with high Uncertainty Avoidance would plan actions and strategies to avoid or mitigate the risk of supply chain disruptions. Thus, for such countries, disruptions should have a limited impact on the stock price.

The long-term Orientation dimension is known as Confucian Dynamism. This dimension indicates a propensity to save for the future, which is reflected in decisions about savings, investment, and perseverance in achieving results. Long-term Orientation is positively associated with savings, insurance, and economic 
growth (Hofstede and Bond, 1988; Park and Lemaire, 2011). In contrast, short-term Orientation generally focuses on achieving quick results. Investments in low probability events such as disruptions could be economically justified when considering long-term objectives (Stecke and Kumar, 2009). The rewards for investment in disruptions mitigation are expected to occur in the long-term rather than the short-term. Future rewards as a virtue of Long-term Oriented cultures make them suitable for disruption management. Therefore, we expect countries with a high value of Long-term Orientation to be better prepared for disruptions and have less impact on the stock price.

Considering the values of Long-term Orientation, we expect the companies in the U.S. to be least prepared for any disruptive events. Moreover, the value of Uncertainty Avoidance is the lowest for the U.S., indicating that companies in the U.S. may face severe consequences of disruptions. In contrast, Japanese companies are expected to fare the best as the values of Uncertainty Avoidance and Long-term orientation is highest for Japan.

\section{Event Study Methodology}

The standard event study methodology is applied to disruptions data to estimate its financial impact on stockholder wealth. The methodology is extensively used in finance and accounting applications. The method is designed to investigate the effects of an event on metrics. In our application, the event is an announcement of a supply chain disruption, while the abnormal stock returns are used as the metric to assess the event's impact. The event study methodology is one of the most frequently used tools in the financial research area. It has been traditionally effective in estimating stock price reactions to events such as the announcements of earnings, dividends, or mergers. The content in this section has been adapted from Kumar, Liu, and Scutella (2015). In a typical application, standard event study methodology is designed to examine the stock returns for a set of companies experiencing a similar event (e.g., a supply chain disruption in our case). The event may occur at a different point in time for a set of companies. However, having a large number of data points would statistically eliminate the effect of factors other than the disruptions on stock outcomes. The stock returns are statistically tested for any abnormal or unexpected returns.

The purpose of most event studies applied in finance and accounting is to assess the stock reactions from a value-relevant event announcement. Supply chain disruptions are value-relevant events that could affect the operations and, thus, the company's profit potential. Moreover, efficient market theory suggests that stock markets are efficient and reflect all value-relevant information. At any instant, a company's stock price is affected by the company-specific and environmental (business) factors. The stock price also reflects expectations about the future earning prospects of a firm. Therefore, information about a value-relevant event such as a supply chain disruption is expected to affect a company's stock returns.

In analyzing disruptions from 10 days before and post disruption announcement, the actual daily stock returns are compared with expected returns. "Conceptually, event study helps differentiate between the stock returns that would have been expected if the supply chain disruption would not have happened (normal returns) and the returns that were observed (abnormal returns)" (Kumar, Liu, Scutella, 2015). The event study methodology is made rigorous and relevant by calculating expected returns using historical data while adjusting for market-wide influence and trends. For more details on event studies, refer to Dodd and Warner (1983), Cowan (1992).

The announcement/publication day of disruption is considered the event day $(t=0)$. To cover for possibilities of insider information, we analyze data and abnormal returns from 5 days prior to the announcement date. Overall, an 11-day window is considered. For robustness of results, both mean and market models are considered. See Brown and Warner (1985) for details of the models. The parameters needed to estimate the abnormal returns were calculated using past 255 trading days (about one year) stock price. The estimation period is $(-300,-46)$. We follow Dodd and Warner (1983) and use standard eventstudy methodology.

An estimation period starting from -300 to -46 days prior to disruption announcement is used in the market model. 


$$
R_{j t}=\alpha_{j}+\beta_{j} R_{m t}+u_{j t}, j=1, \ldots, N ; t=-300, \ldots,-46,
$$

The market model is estimated using the equally-weighted market returns from SP500, SENSEX, and NIKKEI. where $N$ is the number of disruption points in the sample, $R_{j t}$ is the return on stock $j$ for day $t$, $R_{m t}$ is the return on market proxy $m$ for day $t, u_{j t}$ is the random error for stock $j$ for day $t$ and is normally distributed with $E\left[u_{j t}\right]=0, \alpha_{j}$ is the estimated intercept term for stock $j$, and $\beta_{j}$ is the estimated risk coefficient for stock $j$. Hendricks and Singhal (2003) use an estimation window of 200 days. Our longer estimation window of 255 days (-300 to -46) is expected to yield more robust parameter estimates.

We calculate the abnormal returns for each day in the test period. The market model abnormal returns (A.R.) for stock $j$ for day $t$ is defined as

$$
A R_{j t}=R_{j t}-\left(\alpha_{j}+\beta_{j} R_{m t}\right), j=1, \ldots, N ; t=T_{1}, T_{1}+1, \ldots T_{2}
$$

The mean model, abnormal returns for stock $j$ for day $t$, is defined as

$$
A R_{j t}=R_{j t}-\overline{R_{j}}
$$

where $\overline{R_{j}}$ is stock $j$ 's mean return for the estimation period.

For both models $E\left\lfloor A R_{j}\right\rfloor=O$, i.e., no abnormal return is expected in an efficient market in equilibrium. If $E\left[A R_{j}\right\rfloor \neq O$, i.e., abnormal returns are observed, we infer that disruptions cause a change in shareholder wealth. The cumulative abnormal returns for stock $j$ (CAR) over the event window is $C A R_{j}=\sum_{k=T_{1}}^{i} A R_{j k}$. We follow Patell (1976) to test the statistical significance of abnormal returns, which are based on the standardized normal distribution. The standardized abnormal returns (SAR) for stock $j$ in day $t$ is calculated as $S A R_{j, t}=\frac{A R_{j, t}}{S_{j, t}}$. The abnormal return is divided by the standard error from the market model estimation for stock $j$. The average standardized abnormal return (ASAR) for day $t$ is $A S A R_{t}=\frac{1}{N} \sum_{j=1}^{N} S A R_{j, t}$. Finally, for each day, the Z-statistic is calculated as $Z_{t}=\sqrt{N} \bullet A S A R_{t}$. The limiting distribution of $Z_{t}$ is the unit normal, under the null hypothesis that the mean normalized, standardized abnormal return equals zero. Over the testing period, which begins with $T_{1}$ and ends with $T_{2}$, the cumulative normalized, average standardized abnormal return (CASAR) is CASAR $_{T_{1}, T_{2}}=\left(\frac{1}{N}\right) \frac{\sum_{t=T_{1}}^{T_{2}} \sum_{j=1}^{N} S A R_{j, t}}{\sqrt{T_{2}-T_{1}+1}}$. Then, the Z-statistic is $Z_{T_{1}, T_{2}}=\sqrt{N} \bullet C A S A R_{T_{1}, T_{2}}$, and has a unit normal limiting distribution under the null hypothesis that the cumulative normalized, average standardized prediction error over the period from $T_{1}$ through $T_{2}$ equals zero. We also perform a non-parametric sign test to make inferences about the sign (positive or negative) of abnormal returns in the estimation period for robustness. 


\section{ANALYSIS AND RESULTS}

We now present the empirical findings of the event study methodology applied to the disruption data from the US, India, and Japan. As indicated earlier, our study builds on a seminal paper by Hendricks and Singhal (2003) and enriches the literature by focusing on multiple countries and competitors. Some of the results in this paper corroborate the findings in Filbeck, Kumar, Liu, Zhao (2015), Kumar, Liu, and Scutella (2015), and Filbeck, Kumar, Zhao (2014). Other results are new to the literature.

Table 2 reports event study results for disruptions in Indian, Japanese, and U.S. companies. The results are obtained using a market model. The table reports percentage abnormal returns starting from 10-days prior to the 10-days post-announcement date, covering a 21-days window around the bad news announcement. Day 0 represents the date of public announcement in one or more news outlets to collect data. The percentage is calculated based on the trading stock price for each company. A negative mean abnormal stock return indicates that the investors do not view the news favorability and expect that the news has a damaging impact on the future earning potential for the company. The table also reports the significance of each of the returns for the three countries written on the 21-day window. Figure 2 plots the data from Table 2. The figure reveals that the variability of returns is highest for India, followed by the U.S. and then Japan.

TABLE 2

MARKET MODEL EVENT STUDY RESULTS: ABNORMAL RETURNS FOR DISRUPTIONS IN INDIAN, JAPANESE, AND THE U.S. COMPANIES

\begin{tabular}{llll}
\hline \hline & & Mean Abnormal Returns (in percentage) \\
\hline Day & India & Japan & U.S. \\
\hline-11 & 0.05 & 0.01 & -0.01 \\
-10 & 0.20 & 0.06 & -0.02 \\
-9 & $-0.61^{*}$ & -0.12 & -0.08 \\
-8 & $-0.53^{*}$ & 0.15 & $0.20^{*}$ \\
-7 & $0.62^{* *}$ & $-0.07 \$$ & 0.00 \\
-6 & 0.24 & -0.08 & -0.09 \\
-5 & 0.13 & $-0.17^{*}$ & $0.03 \$$ \\
-4 & -0.27 & 0.13 & $-0.24^{*}$ \\
-3 & $-0.50^{* * *}$ & 0.05 & -0.02 \\
-2 & $-0.39 \$$ & $-0.26^{* *}$ & 0.14 \\
-1 & $-0.66^{* * *}$ & $-0.21 \$$ & $-0.68^{* * *}$ \\
0 & $-0.58^{*}$ & $0.00^{*}$ & 0.00 \\
+1 & $0.06 \$$ & -0.22 & -0.02 \\
+2 & 0.09 & 0.02 & 0.08 \\
+3 & -0.30 & -0.03 & 0.01 \\
+4 & $-0.27 \$$ & 0.26 & -0.01 \\
+5 & -0.24 & -0.19 & $0.55^{*}$ \\
+6 & $-0.26 \$$ & $-0.40^{* *}$ & 0.04 \\
+7 & -0.10 & 0.39 & -0.01 \\
+8 & -0.16 & -0.13 & 0.13 \\
+9 & 0.01 & -0.01 & -0.13 \\
+11 & -0.16 & -0.61 & -0.11 \\
\hline+ & 0.15 & -0.08 \\
\hline
\end{tabular}

$\overline{\$, * * * \text {, and } * * * \text { represent the significance at } 0.10,0.05,0.01,0.001 \text { levels, respectively. Day } 0 \text { represents the date of }}$ public announcement of bad news. 
Table 2 clearly shows that bad news events cause a significant stock market decline in companies across the globe. The decline is primarily concentrated around the date of the announcement. Here we focus on three days prior to the date of the announcement. Considering three days is logical as a bad event on a Friday may not be officially reported until Monday, giving a 3-day window for the event date and its announcement date. For India a significant stock declines of $-0.50 \%,-0.39 \%,-0.66 \%$, and $-0.58 \%$ were observed on days $-3,-2,-1$ and 0 , respectively. For Japan, significant declines were $-0.26 \%$ and $-0.21 \%$ on days -2 and -1 , respectively. Finally, for the U.S., the only significant decline of $-0.68 \%$ around the announcement window was observed on day -1 .

\section{FIGURE 2 \\ DAILY PERCENTAGE ABNORMAL RETURNS FROM 10-DAYS PRIOR TO 10-DAYS POST ANNOUNCEMENT}

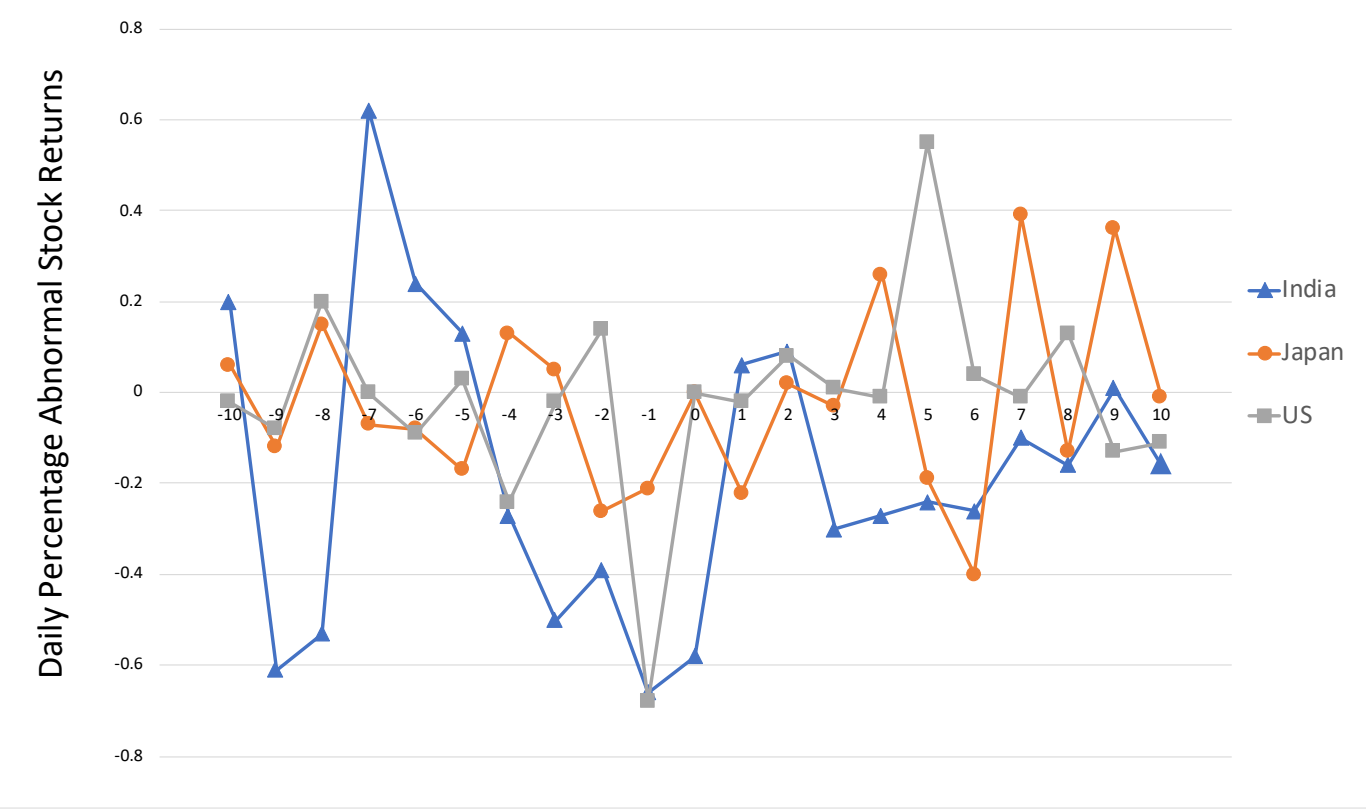

As per our expectation, the abnormal returns for the U.S. are quantitatively higher than that of Japan. A t-test for the difference in the abnormal returns for Japan and the U.S. shows that the U.S. experiences significantly more negative stock decline than Japan. This supports our expectations as per the national culture dimensions of Long-term Orientation and Uncertainty Avoidance. Although qualitatively, in India, stocks seem to experience a more severe decline following a disruption, the difference is not statistically significant.

Table 2 also reveals the relative maturity of stock markets and the laws governing the stock markets. Stock markets in the U.S. are most mature, with numerous laws stipulating trading and information access rules. India is a developing country with an immature stock market. Although Japan is a developed country, the stock markets do not have strict laws. These aspects are observed in the results of Table 2. For India, a significant stock decline was observed as early as nine-day prior to the public announcement. Note that a stock decline of -0.61 is reported for day -9 . This may indicate that some select investors may have had information about the upcoming bad news earlier than the public release date. Insider trading could be a possible cause of the decline. In the case of Japan, a significant decrease of -0.17 was observed five days before day 0. Despite being a developed economy, insider trading laws are not well defined in Japan. Moreover, lawsuits related to insider trading are extremely rare. These factors may help explain the significant stock decline on Day -5. In contrast to Japan and India, the most significant stock decline in the 
U.S. is observed only on day -1 . This is expected because of strict trading legislation as well as a mature stock market.

Of the three countries, the U.S. ranks lowest on Long-term Orientation. This may indicate that the decision-makers may focus on short-term goals. This myopic focus may suggest that bad news may encourage investors to impulsively trade, leading to a sharper decline than warranted. If the market experiences a larger than expected decline, there will be a correction in the stock price later. Note that for the U.S., a significant stock price increase of 0.55 percent is observed on day 5 . Such an increase is only in the case of the U.S. This further ascertains the impact of national culture on the stock markets.

To further demonstrate the impact of national culture, we now focus only on significant and negative stock impact from disruptions. Figure 3 plot the significant negative returns for the three countries for the window of $(-10,+10)$. It is clear that the stock returns for Japan are closest to 0. Moreover, these returns are spread across time in both prior and post-announcement dates. This further demonstrates the impact of the national culture dimension, Long-term Orientation. For India and the U.S., significant negative returns are observed on or before the announcement day. The extent of decline for the U.S. is statistically greater than that of Japan. The high degree of stock decline for India could be explained by the fact that India is a developing country, and its stock market has not yet matured.

FIGURE 3

\section{DAILY NEGATIVE AND SIGNIFICANT PERCENTAGE ABNORMAL RETURNS}

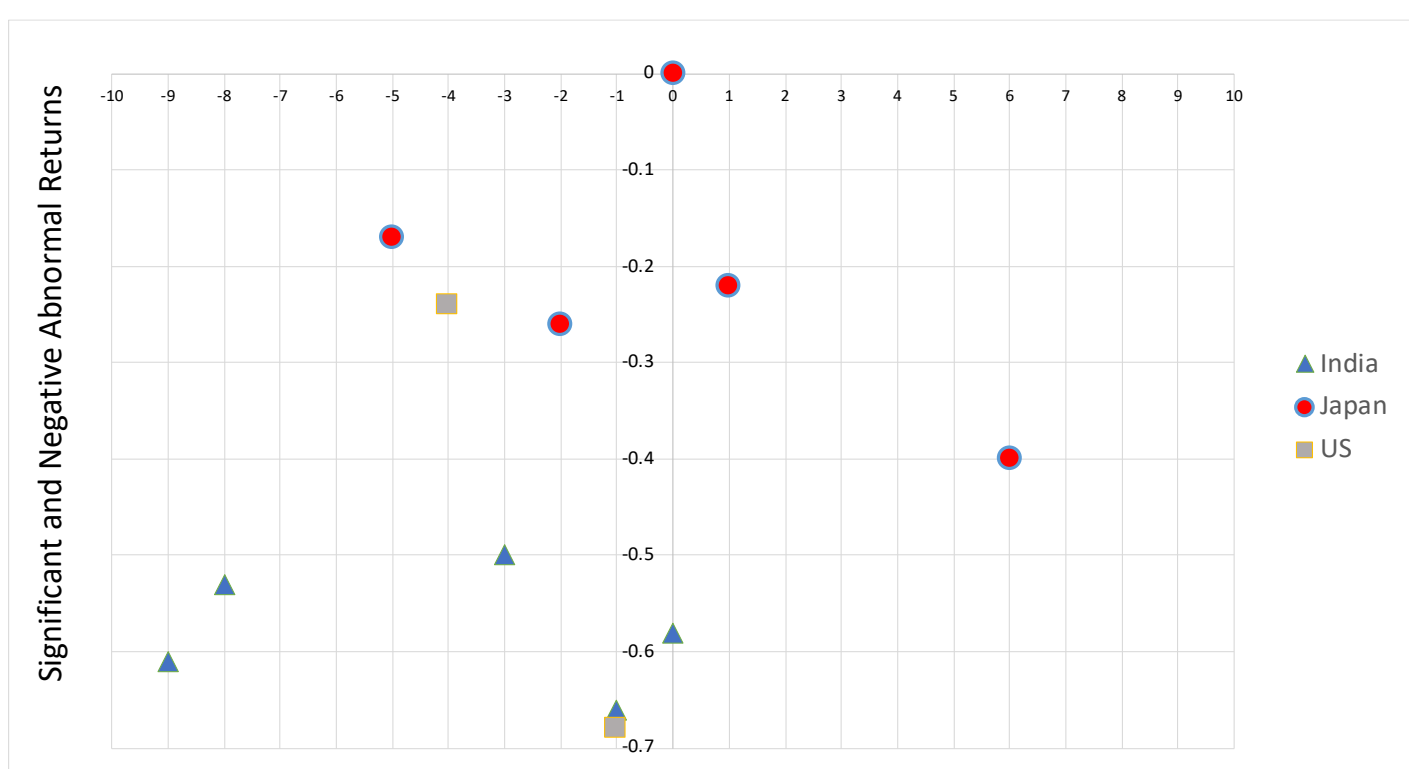

We now focus on the company culture because of the domicile base of a company. Management literature seems to argue that Japanese companies in the U.S. have strong disruption management and mitigation abilities. Several anecdotal examples support this premise. To see if the company culture affects the stock decline because of bad news, we extract the data for Japanese and American automakers from the database of U.S. companies. We choose the auto industry as it provides a case where there is a clear distinction of domicile of companies. For example, Toyota and Honda are considered Japanese Automakers, while companies such as Ford, GM, and Chevrolet are often referred to as American Automakers. Although note that a significant portion of these cars is made in the U.S. Judging by the manufacturing base, there is no significant difference between these companies.

Furthermore, we divided the data into Bear and Bull market cycles. This is important because finance literature has shown that investors react to bad news differently based on the market's direction. While analyzing the dataset for automakers, we found that bad news does not cause any significant decline in the 
Bull market. However, significant differences were observed in the Bearish market. Table 3 reports stock decline for Japanese and U.S. automakers. As reported in the table, the stock decline in the $(-5,+5)$ window is $-2.12 \%$ and $-6.72 \%$ for Japanese and U.S. automakers, respectively. Investors punish U.S. companies more than Japanese companies. This difference could also be attributed to the company culture that encourages disruption preparation and mitigation strategies. It is clear that national culture permeates company culture even if it operates in a different country.

TABLE 3

MARKET MODEL EVENT STUDY RESULTS: CUMULATIVE ABNORMAL RETURNS FOR DISRUPTIONS IN INDIAN, JAPANESE, AND THE U.S. COMPANIES

\begin{tabular}{lll}
\hline \hline Window & Mean Abnormal Returns (Bear Market) \\
\hline & Japan & U.S. \\
\hline$(-5,+5)$ & $-2.12^{* *}$ & $-6.72 * *$ \\
\hline$\$, * * *$, and $* * *$ represent the significance at $0.10,0.05,0.01,0.001$ levels, respectively.
\end{tabular}

\section{CONCLUSIONS}

In this paper, we studied the factors that affect the extent of stock market decline following a public announcement of bad news. Using disruptions as a case of bad news, we studied companies in Japan, India, and the U.S. We proposed that national culture affects disruptions planning and preparedness, which in turn has an impact on the negative impact of disruptions.

We hand-collected disruptions data for India, Japan, and the U.S. An event study methodology was used to estimate abnormal stock returns starting from 10 days prior to 10 days post disruptions announcement. Our results and analysis show that disruptions have different consequences in the three countries. We observed that the investors in the U.S. punish companies more severely when compared to companies in Japan. Economic development levels and market maturity affect the impact. Finance and stock market regulations also have an effect. Stock markets in Indian and Japan displayed declines days before the public announcement. For the Indian market, this could be because of the maturity level, while for Japan, the reason could be lax investor legislation. In contrast, the U.S. companies show stock decline only on the announcement date.

We also found that Japanese automakers in the U.S. fare better than American automakers. The stock decline for Japanese automakers was found to be significantly lower than that of American automakers. This indicates that company culture derived from domicile plays a role in stock impact from disruptions besides national culture.

\section{REFERENCES}

Brown, S.J., \& Warner, J.B. (1985). Using Daily Stock Returns: The Case of Event Studies. Journal of Financial Economics, 14, 3-31.

Cowan, A.R. (1992). A Nonparametric Event Study Tests. Review of Quantitative Finance and Accounting, 2(4), 343-358.

Dodd, P., \& Warner, J. (1983). On corporate governance. Journal of Financial Economics, 11(1), 401438.

Filbeck, M.G., Kumar, S., \& Zhao, X. (2014). Effect of Supply Chain Disruptions on Competitor's Shareholder Wealth. Journal of Business and Economic Perspectives, 41(2), 24-66.

Filbeck, M.G., Kumar, S., Liu, J., \& Zhao, X. (2015). Shareholder Wealth and Automobile Industry Supply Chain Disruptions. Working paper, Valparaiso University.

Hendricks, K.B., \& Singhal, V.R. (2003). The Effect of Supply Chain Glitches on Shareholder Value. Journal of Operations Management, 21(5), 501-522. 
Hendricks, K.B., \& Singhal, V.R. (2005a). An empirical analysis of the effect of supply chain disruptions on long-run stock price performance and equity risk of the firm. Production and Operations Management, 14(1), 35-52.

Hendricks, K.B., \& Singhal, V.R. (2005b). Association between supply chain glitches and operating performance. Management Science, 51(5), 695-711.

Hofstede, G. (2013). National Culture Dimensions. Retrieved July 10, 2013, from http://geerthofstede.com/national-culture.html

Hofstede, G., \& Bond, M.H. (1988). Confucius \& Economic Growth: New Trends in Culture's Consequences. Organizational Dynamics, 16(4), 4-21.

Hofstede, G., Hofstede, G.J., \& Minkov, M. (2010). Cultures and Organizations: Software of the Mind. McGraw Hill, New York, NY.

Kumar, S., Liu, J., \& Caliskan, O.D. (2015). The interaction of culture and supply chain disruptions management. Journal of Applied Business and Economics (forthcoming).

Kumar, S., Liu, J., \& Scutella, J. (2015). Stockholder Wealth and Supply Chain Disruptions in Indian Companies. International Journal of Physical Distribution \& Logistics Management, 45(9/10), 938-958.

Mello, J.E., \& Stank, T.P. (2005). Linking Firm Culture and Orientation to Supply Chain Success, International Journal of Operations \& Production Management, 35(7/8), 542-554.

Pagell, M., Katz, J.P., \& Sheu, C. (2005). The Importance of National Culture in Operations Management Research. International Journal of Operations \& Production Management, 25(3/4), 371-394.

Park, S.C., \& Lemaire, J. (2011). Culture Matters: Long-Term Orientation and the Demand for Life Insurance. Insurance and Risk Management Working Paper, The Wharton School, University of Pennsylvania.

Patell, J.M. (1976). Corporate forecasts of earnings per share and stock price behavior: Empirical tests. Journal of Accounting Research, 14(2), 246-276.

Sheffi, Y. (2007). The Resilient Enterprise: Overcoming Vulnerability for Competitive Advantage. MIT Press, pp. 211-216.

Stecke, K.E., \& Kumar, A. (2009). Sources of Supply Chain Disruptions, Factors that Breed Vulnerability, and Mitigating Strategies. Journal of Marketing Channels, 16(3), 193-226.

Tsui, A.S., Nifadkar, S.S., \& Ou, A.Y. (2007). Cross-National, Cross-Cultural Organizational Behavior Research: Advances, gaps, and Recommendations. Journal of Management, 33(3), 426-478. 